\title{
Human hexokinase II: localization of the polymorphic gene to chromosome 2
}

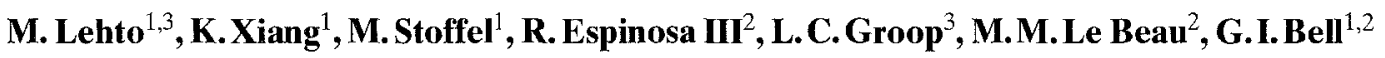 \\ ${ }^{1}$ Howard Hughes Medical Institute, Department of Biochemistry and Molecular Biology, University of Chicago, Chicago, Illinois, USA \\ ${ }^{2}$ Department of Medicine, University of Chicago, Chicago, Illinois, USA \\ ${ }^{3}$ Department of Biochemistry and Fourth Department of Medicine, Helsinki University, Helsinki, Finland
}

\begin{abstract}
Summary. Type 2 (non-insulin-dependent) diabetes mellitus is characterized by decreased levels of glucose 6-phosphate in skeletal muscle. It has been suggested that the lower concentrations of glucose 6-phosphate contribute to the defect in glucose metabolism noted in muscle tissue of subjects with Type 2 diabetes or subjects at increased risk of developing Type 2 diabetes. Lower levels of glucose 6-phosphate could be due to a defect in glucose uptake, or phosphorylation, or both. Hexokinase II is the isozyme of hexokinase that is expressed in skeletal muscle and is responsible for catalysing the phosphorylation of glucose in this tissue. The recent demonstration that mutations in another member of this family of glucose phosphorylating enzymes, glucokinase, can lead to
\end{abstract}

the development of Type 2 diabetes prompted us to begin to examine the possible role of hexokinase II in the development of this genetically heterogeneous disorder. As a first step, we have cloned the human hexokinase II gene (HK2) and mapped it to human chromosome 2 , band p13.1, by fluorescence in situ hybridization to metaphase chromosomes. In addition, we have identified and characterized a simple tandem repeat DNA polymorphism in $H K 2$ and used this DNA polymorphism to localize this gene within the genetic linkage map of chromosome 2 .

Key words: Genetics, DNA polymorphism, glucose, phosphorylation, glycolysis, chromosome 2, insulin resistance.
Insulin resistance is characterized by a defect in the nonoxidative metabolism of glucose in muscle [1]. In vivo studies using ${ }^{31} \mathrm{P}$ nuclear magnetic resonance measurements of muscle glucose 6-phosphate (G6P) levels have shown that concentrations of this intermediate of glucose metabolism were much lower in subjects with Type 2 (non-insulin-dependent) diabetes mellitus than in ageand weight-matched control subjects [2]. The lower concentration of G6P in muscle of diabetic subjects may be due to a defect in the uptake or phosphorylation of glucose. The phosphorylation of glucose in mammalian tissues is mediated by a family of hexose phosphotransferases [3]. These include hexokinases I, II and III, and glucokinase, of which hexokinase II is the isozyme expressed in skeletal muscle. The recent demonstration that mutations in glucokinase, the enzyme responsible for the phosphorylation of glucose in pancreatic beta cells and hepatocytes, are associated with an autosomal dominant form of Type 2 diabetes with onset during childhood [4-7] prompted us to consider a possible role of hexokinase II in the development of Type 2 diabetes. As a first step in these studies, we have localized the human hexokinase II gene (HK2) by fluorescence in situ hybridization to chromosome 2, band p13.1. In addition, we identified and char- acterized a simple tandem repeat DNA polymorphism (STRP) in $H K 2$ and used this STRP to localize $H K 2$ within the genetic linkage map of chromosome 2.

\section{Materials and methods}

\section{General methods}

Standard methods were carried out as described in Sambrook et al. [8]. DNA sequencing was done by the dideoxynucleotide chain termination procedure after subcloning appropriate DNA fragments into M13 mp18 or M13 mp19.

\section{Isolation of the human $\mathrm{HK} 2$ gene}

A human male placenta genomic library in $\lambda$ FIXII (Stratagene, La Jolla, Calif., USA; catalogue no. 946203) was screened by hybridization with a ${ }^{32} \mathrm{P}-1$ abelled rat hexokinase II cDNA fragment corresponding to nucleotides $1775-2440$ of the rat cDNA sequence [9]. Sixteen clones were obtained and designated $\lambda \mathrm{hHK} 2-1$ to -16 . 


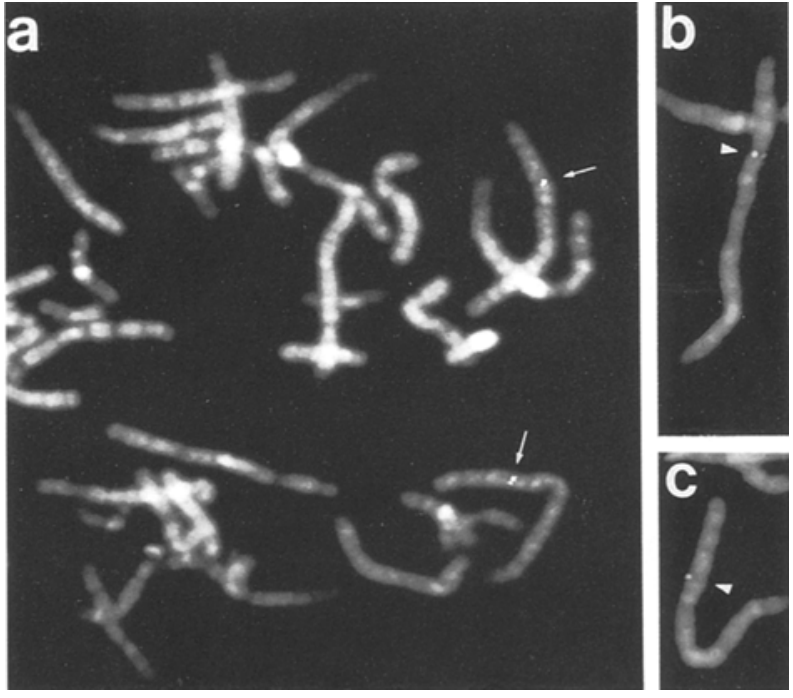

Fig.1a-c. In situ hybridization of biotin-labelled $\lambda H$ K2-7 DNA to human metaphase cells from phytohaemagglutinin-stimulated peripheral blood lymphocytes. a Partial metaphase spread. The chromosome 2 homologues are identified with arrows; specific labelling was observed at 2 p13.1. b and $\mathbf{c}$ Two chromosome 2 homologues showing specific labelling at 2p13.1 (arrowhead). Images were obtained using a Zeiss Axiophot microscope coupled to a thermoelectrically cooled charge coupled device camera. Separate images of DAPI-stained chromosomes and the hybridization signal were merged using image analysis software (IPLab Spectrum and GeneJoin)

\section{Fluorescence in situ chromosomal hybridization}

Human metaphase chromosomes were prepared from phytohaemagglutinin-stimulated blood lymphocytes. Fluorescence in situ hybridization was performed as described previously [10] using the clone $\lambda \mathrm{hHK} 2-7$ which has an insert of approximately 15 kilobases $(\mathrm{kb})$. Probes were prepared by nick-translation using Biotin-11dUTP (Boehringer Mannheim, Indianapolis, Ind., USA). Hybridization with biotin-labelled probes was detected with fluoresceinconjugated avidin (Vector Laboratories, Burlingame, Calif., USA). Chromosomes were identified by staining with 4,6-diamidino-2-phenylindole-dihydrochloride (DAPI).

\section{Identification of an STRP}

From each $H K 2$ genomic clone, $1 \mu \mathrm{g}$ of DNA was digested with BamHI and after electrophoretic separation blotted onto a nitrocellulose filter and hybridized with ${ }^{32} \mathrm{P}$-labelled poly ( $\mathrm{dA}-\mathrm{dC}$ )-poly (dG-dT) (Pharmacia LKB Biotechnology, Piscataway, NJ, USA) as described previously [11]. A $2.3 \mathrm{~kb}$ fragment of $\lambda \mathrm{hHK} 2-7$ showed a strong hybridization signal. This fragment was isolated, subcloned into the BamHI site of M13 mp18 and sequenced.

\section{Amplification of the STRP}

Two primers flanking the CA repeat-rich region identified in $H K 2$, HK2-1 and HK2-2, were selected by inspection and used to amplify the approximately 224 base pair (bp) region containing this repetitive sequence. The polymerase chain reaction (PCR) was performed using ${ }^{32}$ P-labelled HK2-1 and unlabelled HK2-2. DNA was denatured at $94^{\circ} \mathrm{C}$ for $5 \mathrm{~min}$, followed by 30 cycles of denaturation at $94^{\circ} \mathrm{C}$ for $1 \mathrm{~min}$, annealing at $60^{\circ} \mathrm{C}$ for $30 \mathrm{~s}$, extension at $72^{\circ} \mathrm{C}$ for $90 \mathrm{~s}$ and a final extension step of $10 \mathrm{~min}$. The PCR products were resolved on a $5 \%$ denaturing polyacrylamide gel. The PCR was carried out in a volume of $25 \mu \mathrm{l}$ containing $50 \mathrm{mmol} / 1 \mathrm{KCl}, 10 \mathrm{mmol} / \mathrm{l}$ Tris- $\mathrm{HCl}$, $\mathrm{pH} 8.3,1.5 \mathrm{mmol} / 1 \mathrm{MgCl}_{2}, 200 \mu \mathrm{mol} / \mathrm{l}$ each of dATP, dCTP, dGTP and dTTP, $0.1 \mu \mathrm{g}$ of DNA, 10 pmoles of each primer and 1.5 units of Taq polymerase in a GeneAmp 9600 PCR System (Perkin Elmer Cetus, Norwalk, Conn., USA).

\section{Linkage mapping of the HK2 STRP in the CEPH database}

Ten families $(28,102,884,1332,1344,1347,1362,1413,1416$ and 1418) of the Centre d'Etude Polymorphisme Humain (CEPH) database [12] were typed using the STRP identified in $H K 2$. Two-point and multipoint linkage analyses were performed using the CLODSCORE and CILINK computer programs of the LINKAGE package [13] and marker data in the CEPH database, version 6.

\section{Results}

\section{Cloning and chromosomal localization of human $\mathrm{HK} 2$}

A segment of rat hexokinase II corresponding to nucleotides 1775-2440 of the published cDNA sequence was amplified in vitro from rat skeletal muscle cDNA using the primers 5'-AGACTTCTTGGCCTTGGGATC-3' and 5'ATGCCGCTGATCATCTTCTC-3'. The sequence of the $666 \mathrm{bp}$ PCR product was identical to that of the corresponding region of rat hexokinase II cDNA. We used this partial rat hexokinase cDNA as a probe to screen a human genomic library in phage $\lambda$. Sixteen clones were isolated. The partial sequence of $\lambda \mathrm{HK} 2-7$ (data not shown) identified three exons corresponding to exons $13-15$ of the rat hexokinase gene [14]. There was $90.5 \%$ nucleotide and $97.6 \%$ amino acid sequence identity with the sequence of rat hexokinase II mRNA and protein in this region. This degree of nucleotide and amino acid sequence identity suggested that we had indeed isolated the human $H K 2$.

The technique of fluorescence in situ hybridization in which biotin-labelled $\lambda \mathrm{HK} 2-7$ DNA was hybridized to normal human metaphase chromosomes was used to determine the chromosomal localization of $H K 2$. Hybridization of the $H K 2$-specific probe resulted in specific labelling only of chromosome 2 (Fig. 1). Examination of 25 cells showed specific labelling of 2 p13.1 on four chromatids in 14 cells, three chromatids in 7 cells, two chromatids in 3 cells, and one chromatid in 1 cell. Similar results were obtained in an additional hybridization experiment using this probe. Thus, $H K 2$ is localized to chromosome 2 , band $\mathrm{p} 13.1$.

\section{Identification and characterization of an STRP in HK2}

The sixteen human $H K 2$ genomic clones were screened for the presence of STRPs by hybridization with ${ }^{32} \mathrm{P}-\mathrm{la}$ belled poly (dA-dC)-poly (dG-dT). One such sequence of the form (CA) 20 was found in $\lambda \mathrm{hHK} 2-7$ (Fig. 2a). Assuming that the organization of the human and rat hexokinase II genes are identical, this STRP is predicted to be in the 
M. Lehto et al.: Human hexokinase II gene

1 AGTGTGGCTGCATGGGTTGGGAGGAAGATTAACTCAAGCGTCGTTCAGCA TCACACCGACGTACCCAACCCTCCTTCTAATTGAGTTCGCAGCAAGTCGT HK2-1

51 GTPRAGTTGCACTGTGTGTCAAGCAATGCTCTCAGCACTGGCGTTCAGG CAAATCACACGTGACACACAGTTCGTTACGAGAGTCGTGACCGCAAGTCC

101 AGTGACCACAACAAAGCTTTGTTCTATAAAGTCCATGACCTAGTGGCAGG TCACTGGTGTTGTTTCGAAACAAGATATTTCAGGTACTGGATCACCGTCC

151 TGCTGTTAAGAGCTGTGAAACACACACACACACACACACACACACACACA ACGACAATTCTCGACACTTTGTGTGTGTGTGTGTGTGTGTGTGTGTGTGT

201 CACACACACAGTAAAGGAATAAAAGAATGGCCAACCTTCCATAAGCAAAA GTGTGTGTGTCATMTCCTTATMTTCTTACCGGT'TGGAAGGTATTCGTTTT

251 CAGCCATGAGGGCTGCTGGTTGCACATTTTTATGGTTATTTCTTGATTAT GTCGGTACTCCCGACGACCAACGTGTAAAAATACCAATAAAGAACTAATA HK2 -2

301 ATGCTAAACAAGGGGTGTAT

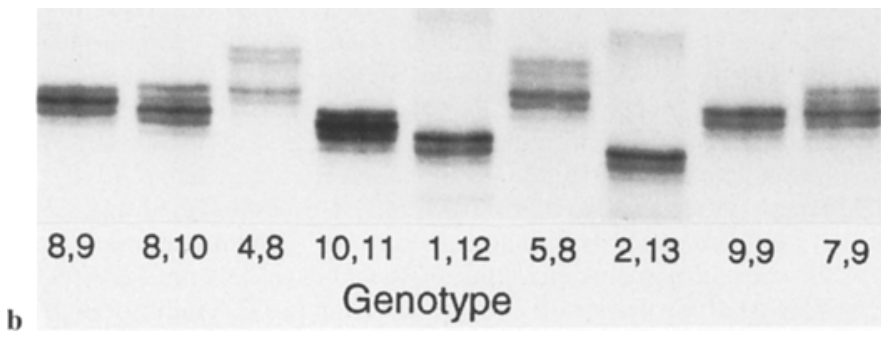

Fig.2a, b. Simple tandem repeat DNA polymorphism (STRP) in human hexokinase II gene. a Nucleotide sequence of the polymorphic region. The sequences of the primers used to amplify this region are indicated in boldface type. $\mathbf{b}$ Polymerase chain reaction amplification of $H K 2$ STRP. The genotypes of the unrelated individuals studied here are shown at the bottom of the figure. The DNA sequence has been deposited in the GenBank database with accession number, L15343. The $H K 2$ genotypes of individuals $1332-01$ and $1332-02$ of the CEPH database are 10,10 and 3,10 , respectively

Table 1. Characterization of simple tandem repeat DNA polymorphism in $H K 2$

\begin{tabular}{llll}
\hline & & \multicolumn{2}{l}{ Allele frequencies } \\
\cline { 3 - 4 } Allele & $\begin{array}{l}\text { Size } \\
\text { (base pairs) }\end{array}$ & $\begin{array}{l}\text { Caucasian } \\
\text { subjects } \\
(n=32)\end{array}$ & $\begin{array}{l}\text { Chinese } \\
\text { subjects } \\
(n=50)\end{array}$ \\
\hline 1 & 244 & - & 0.01 \\
2 & 240 & - & 0.03 \\
3 & 238 & 0.02 & 0.01 \\
4 & 236 & - & 0.01 \\
5 & 234 & 0.02 & - \\
6 & 232 & - & 0.01 \\
7 & 230 & 0.02 & 0.01 \\
8 & 228 & 0.14 & 0.12 \\
9 & 226 & 0.15 & 0.05 \\
10 & 224 & 0.57 & 0.67 \\
11 & 222 & 0.06 & 0.05 \\
12 & 220 & - & 0.03 \\
13 & 218 & 0.02 & - \\
Heterozygosity & & 0.63 & 0.53 \\
PIC value & & 0.60 & 0.51 \\
\hline
\end{tabular}

${ }^{a}$ The polymorphic information content (PIC) value is another measure of the degree of polymorphism of a marker. It is defined as the probability that the marker genotype of a given offspring will allow deduction of which of the two marker alleles of the affected parent it had received [18]
Table 2. Two-point lod scores for linkage of $H K 2$ to DNA markers on chromosome 2

\begin{tabular}{lll}
\hline Locus & $\begin{array}{l}\text { Recombination } \\
\text { fraction }\left(\theta_{\mathrm{m}}=\theta_{\mathrm{f}}\right)\end{array}$ & $\begin{array}{l}\text { Lod score } \\
\left(Z_{\text {max }}\right)\end{array}$ \\
\hline D2S147 & 0.14 & 4.73 \\
$D 2 S 134$ & 0.14 & 4.24 \\
$D 2 S 136$ & 0.11 & 5.66 \\
$D 2 S 145$ & 0.03 & 4.72 \\
$D 2 S 45$ & 0.00 & 5.71 \\
TGFA & 0.00 & 4.47 \\
$D 2 S 169$ & 0.09 & 5.90 \\
$D 2 S 38$ & 0.10 & 6.47 \\
$D 2 S 62$ & 0.11 & 6.68 \\
\hline
\end{tabular}

Multipoint analysis indicated that the most likely order of these loci is pter- $D 2 S 147-(D 2 S 134, D 2 S 136)-D 2 S 145-(D 2 S 45, H K 2, T G F A)$ (D2S169,D2S38)-D2S62 -cen. A more complete description of each of these loci can be obtained from the Genome Data Base (William H. Welch, Medical Library, The Johns Hopkins University, Baltimore, MD 21205, USA)

intron between exons 13 and 14. Amplification of this repeat sequence using PCR showed that it was highly polymorphic with 13 alleles (Fig. 2b, Table 1). Note that the amount of radioactivity incorporated into the two alleles may differ considerably, e.g. individuals with genotypes $1,12,5,8$ and 2,13 in Figure 2 b. This difference in intensity was also seen when this region was amplified with another pair of oligonucleotides. We do not know the reason for this difference.

The heterozygosity, i.e. the proportion of individuals expected to be heterozygous at this locus, of this STRP was 0.63 in a group of 32 unrelated Caucasian subjects and 0.53 in 50 unrelated Chinese subjects. The HK2 STRP showed co-dominant inheritance in ten families.

\section{Localization of HK2 in the framework linkage map of chromosome 2}

Two-point linkage analyses carried out between the $H K 2$ STRP and other chromosome 2 markers in the CEPH database showed significant evidence of linkage (i.e. a lod score of $>3$ ) with nine loci on the short arm of chromosome 2 (Table 2) including TGFA which had previously been mapped by in situ hybridization to $2 \mathrm{p} 13$ [15]. Thus, the linkage studies confirm the localization of $H K 2$ to chromosome 2 . There were no recombinants noted between $H K 2$ and $D 2 S 45$ or $T G F A$. From the linkage map of chromosome $2[16,17]$, the most likely order of these markers is pter-D2S147-(D2S134, D2S136)-D2S145(D2S45, HK2, TGFA)-(D2S169, D2S38)-D2 S62-cen. $H K 2$ is flanked by two highly polymorphic STRPs, $D 2 S 145$ and $D 2 S 169$ [17], and these markers will be useful for typing those families in which $H K 2$ is not fully informative for linkage purposes.

\section{Discussion}

The insulin resistance of Type 2 diabetes is characterized by a defect in glucose metabolism in muscle including decreased levels of G6P [1,2]. Since hexokinase II is respon- 
sible for glucose phosphorylation in muscle cells [3, 14], mutations that affect the function of this enzyme may contribute to the development of insulin resistance and Type 2 diabetes. Preliminary linkage studies in two large Finnish families with classic late-onset Type 2 diabetes suggest that $H K 2$ is not tightly linked to diabetes in these families. However, as Type 2 diabetes is a genetically heterogeneous disorder, this result does not exclude a role for $H K 2$ in the development of diabetes in other families. The STRP that we have identified will facilitate genetic studies of $H K 2$ in subjects with Type 2 diabetes.

Acknowledgements. We thank Mr. A. A. Fernald for technical assistance. These studies were supported by the Howard Hughes Medical Institute, USPHS Grants DK-20595 (to the Diabetes Research and Training Center of the The University of Chicago) and CA-40046 (to M.M.L.), and the Sigrid Juselius Foundation and Research and Science Foundation of Farmos (to M. L. and L. G.). M.S. was supported by a fellowship from the Deutsche Forschungsgemeinschaft.

\section{References}

1. DeFronzo RA, Bonadonna RC, Ferrannini E (1992) Pathogenesis of NIDDM: a balanced overview. Diabetes Care 15:318-368

2. Rothman DL, Shulman RG, Shulman GI (1992) ${ }^{31} \mathrm{P}$ Nuclear magnetic resonance measurements of muscle glucose 6-phosphate: evidence for reduced insulin-dependent muscle glucose transport or phosphorylation in non-insulin-dependent diabetes mellitus. J Clin Invest 89: 1069-1075

3. Ureta T (1982) The comparative isozymology of vertebrate hexokinase. Comp Biochem Physiol 71B: 549-555

4. Vionnet N, Stoffel M, Takeda J et al. (1992) Nonsense mutation in the glucokinase gene causes early-onset non-insulin-dependent diabetes mellitus. Nature 356: 721-722

5. Stoffel M, Froguel Ph, Takeda J et al. (1992) Human glucokinase gene: isolation and characterization and identification of two missense mutations linked to early-onset non-insulin-dependent (type 2) diabetes mellitus. Proc Natl Acad Sci USA 89: 76987702

6. Stoffel M, Patel P, Lo Y-MD et al. (1992) Characterization of a missense glucokinase mutation in maturity-onset diabetes of the young and mutation screening in late-onset diabetes. Nature Genetics 2: 153-156

7. Froguel Ph, Zouali H, Vionnet N et al. (1993) Familial hyperglycemia due to mutations in glucokinase: definition of a subtype of diabetes mellitus. N Engl J Med 328: 697-702
8. Sambrook J, Fritsch EF, Maniatis T (1989) Molecular cloning, a laboratory manual, 2 nd edn. Cold Spring Harbor Laboratory Press, Cold Spring Harbor, NY

9. Thelen AP, Wilson JE (1991) Complete amino acid sequence of the type II isozyme of rat hexokinase, deduced from the cloned cDNA: comparison with a hexokinase from Novikoff ascites tumor. Arch Biochem Biophys 286: 645-651

10. Rowley JD, Diaz MO, Espinosa R et al. (1990) Mapping chromosome band 11 q23 in human acute leukemia with biotinylated probes: identification of $11 \mathrm{q} 23$ translocation breakpoints with a yeast artificial chromosome. Proc Natl Acad Sci USA 87: 93589362

11. Nishi S, Stoffel M, Xiang K, Shows TB, Bell GI, Takeda J (1992) Human pancreatic beta-cell glucokinase: cDNA sequence and localization of the polymorphic gene to chromosome 7, band $\mathrm{p} 13$. Diabetologia 35: 743-747

12. Dausset J, Cann H, Cohen D, Lathrop M, Lalouel J-M, White R (1990) Centre d'Etude Polymorphisme Humain (CEPH): collaborative genetic mapping of the human genome. Genomics 6 : 575-577

13. Lathrop GM, Lalouel JM, Julier C, Ott J (1985) Multilocus linkage analysis in humans: detection of linkage and estimation of recombination. Am J Hum Genet 37: 482-498

14. Printz RL, Koch S, Potter LR et al. (1993) Hexokinase II mRNA and gene structure, regulation by insulin, and evolution. J Biol Chem 268:5209-5219

15. Tricoli JV, Nakai H, Byers MG, Rall LB, Bell GI, Shows TB (1986) The gene for human transforming growth factor $\alpha$ is on the short arm of chromosome 2. Cytogenet Cell Genet 42:94-98

16. NIH/CEPH collaborative mapping group (1992) A comprehensive genetic linkage map of the human genome. Science 258: 6786

17. Weissenbach J, Gyapay G, Dib C et al. (1992) A second-generation linkage map of the human genome. Nature 359: 794-801

18. Ott J (1991) Analysis of human genetic linkage, revised edition. The Johns Hopkins University Press, Baltimore

Received: 29 April 1993

and in revised form: 29 June 1993

Dr. G.I.Bell

Howard Hughes Medical Institute

University of Chicago

5841 S. Maryland Ave., MC1028

Chicago, IL 60637

USA 